\title{
Antioxidant Therapy by Lipoic Acid in Various Illnesses: Reactive Oxygen Species and Oxidative Stress
}

\author{
Peter Kovacic ${ }^{1 *}$ and Wil Weston ${ }^{2}$ \\ ${ }^{1}$ Department of Chemistry and Biochemistry, San Diego State University, USA \\ ${ }^{2}$ Library and Information Access, San Diego State University, USA \\ Submission: December 21, 2017; Published: January 05, 2018 \\ *Corresponding author: Peter Kovacic, Department of Chemistry and Biochemistry, San Diego State University, San Diego, USA, \\ Email: pkovacic@mail.sdsu.edu
}

\section{Abstract}

Lipoic acid (LA) is an effective antioxidant that possesses therapeutic properties in the treatment of various illnesses, including multiple sclerosis (MS), Alzheimer's disease (AD), Parkinson's disease (PD), diabetes, cognitive decline, depression, memory loss, and hemorrhage. Additionally, mechanistic aspects of lipoic acid are addressed.

Keywords: Lipoic acid; Antioxidant; Illness; Reactive oxygen species; Oxidative stress

Abbreviations: LA: Lipoic Acid; OS: Oxidative Stress; OS: Reactive Oxygen Species; AO: Antioxidant; ROS: Reactive Oxygen Species; AD: Alzheimer's Disease; PD: Parkinson's Disease; MS: Multiple Sclerosis; MDA: Malondialdehyde; TBARS: Thiobarbituric Acid Reactive Substances; GSH: Glutathione

\section{Introduction}

The unifying theme of reactive oxygen species (ROS) - oxidative stress (OS) - antioxidant (AO) has been used successfully to rationalize a wide range of physiological activities. There is a plethora of experimental evidence supporting the ROS-OS-AO theoretical framework [1-3]. This evidence includes the generation of the common ROS, lipid peroxidation, degradation products of oxidation, depletion of AOs, effect of exogenous AOs, and DNA oxidation and cleavage products, as well as electrochemical data. This comprehensive unifying mechanism is consistent with the frequent observation that many substances display a variety of activities (e.g. multiple drug properties), as well as toxic effects. It is important to recognize that mode of action in the biodomain is often involved with many physiological actions and is multifaceted. In addition to the ROSOS-AO approach, other aspects may pertain, such as, enzyme inhibition, allosteric effects, receptor binding, electrochemistry, cell signaling, metabolism and physical factors.

Lipoic acid (LA) (Figure 1) is a potent AO, which has been reported to alleviate a wide variety of illnesses involving ROSOS. The present article addresses the following ones: multiple sclerosis (MS), Alzheimer's disease, diabetes, cognitive decline, depression, memory loss, and hemorrhage. The dithiol metabolite (dihydro LA) (Figure 2) from reduction is even more potent as an $\mathrm{AO}[4,5]$. Two possible mechanisms (Scheme 1) of thiol AO activity are presented which has received recent attention. A number of AOs can also act as pro-oxidant under the appropriate conditions. Application to thiols is presented in (Scheme 2).

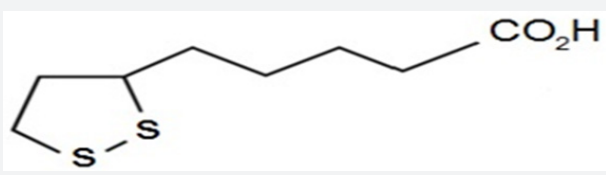

Figure 1: Lipoic acid (LA).

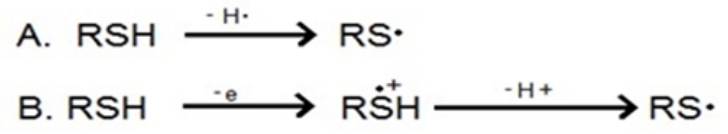

Scheme 1: Mechanisms of thiol AO activity.<smiles>O=C(O)CCCCC(S)CCS</smiles>

Figure 2: Dithiol metabolite of LA 


\section{Novel Approaches in Drug Designing \& Development}

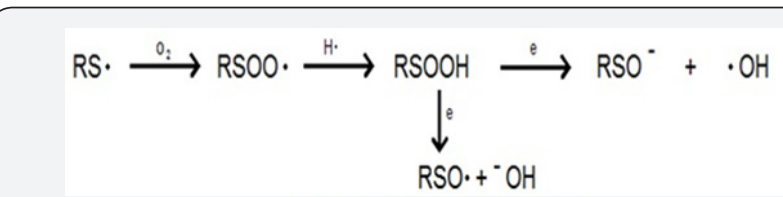

Scheme 2: Prooxidant effect of thiol radical.

\section{Discussion}

Since ROS and OS are known to play a role in MS, LA was investigated as an AO. LA was shown to exert protective effects including decrease in OS and prevention of apoptosis [6]. There is also reduction of redox signaling. LA is reduced to a dithiol which is a more powerful AO. OS plays a major role in MS and inflammation. A study of the AOlipoic acid demonstrated improvement among MS patients [7]. LA lessoned hypertension, while decreasing levels of superoxide and malondialdehyde (MDA) [8]. AO capacity was enhanced. AOis characterized by enhanced OS and decreased AOs [9]. Focus was on recovery from ROS by use of AOs, such as LA, n-acetylcysteine and vitamin E. A multi-targeted approach is recommended. Therapeutic use of LA in diabetes was studied [10]. OS is a factor in many diseases. Therefore, beneficial effects are noted from use of AOs, such as LA. Various factors are involved in depression, including oxidative and nitrosative stress, as well as damage to lipid membranes and decrease in AO levels [11]. Promising compounds for reversal of the adverse affects include LA. OS is importantly involved in brain diseases, such as Alzheimer's disease (AD) and Parkinson's disease (PD). LA is known to bestow neuroprotection via the AO property [12]. A study found that LA was able to improve memory. Reversal of OS was observed, together with a favorable effect on lifespan [13]. Elevated MDA levels after hemorrhage were reduced by LA treatment [14]. The acid lessons cerebral vasospasms by its strong AO property. $\mathrm{AD}$ arises from ROS and RNS resulting in OS [15]. AOs such as LA, offer treatments for neurodegenerative diseases. LA and the dithiol derivative are strong AOs which are promising for treatment of neurodegenerative diseases, such as $\mathrm{AD}$ [16]. The role of OS is addressed.

Hemorrhage is associated with ROS, DNA fragmentation, malondialdehyde (MDA) formation plus decrease in glutathione (GSH). LA treatments reversed the adverse factors [17]. The disulfide enhances AO activity and inhibited free radical generation. OS occurs during seizures such as epilepsy [18]. Brain damage is induced by oxidative processes. A strong protective affect was achieved by use of LA. Aging dogs develop cognitive decline and oxidative damage [19]. These animals trialed with an AO diet, including LA, showed cognitive improvement. The aged brain shows increases in ROS. The AO diet improves cognition by maintaining mitochondrial homeostasis. Lipopolysaccarides (LPS) generate ROS that play a role in brain injury [20]. LPS induced OS and shocked with increase in thiobarbituric acidreactive substances (TBARS) and $\mathrm{H} 2 \mathrm{O} 2$. Addition of LA after LPS increased thiol content and decreased TBARS and H2O2. LA protects the brain against OS [21]. LA exerts many biofunctions, in part by destroying ROS. The review discusses treatment of various diseases involving OS. LA may be effective in treatment of MS, AD and diabetes.

\section{References}

1. Kovacic P, Thurn LA (2005) cardiovascular toxicity from the perspective of oxidative stress, electron transfer, and prevention by antioxidants. Curr Vasc Pharmacol 3(2):107-117.

2. Kovacic P, Somanathan R (2008) Ototoxicity and noise trauma: electron transfer, reactive oxygen species, cell signaling, electrical effects, and protection by antioxidants: practical medical aspects.Med Hypotheses 70(5): 914-923.

3. Halliwell B, Gutteridge JMC (1999) Free Radicals in Biology and Medicine. Oxford University Press, Newyork pp. 1-897.

4. Biewenga GP, Haenen GR, Bast A (1997) The pharmacology of the antioxidant lipoic acid. Gen Pharmacol 29(3): 315-331.

5. Shay KP, Moreau RF, Smith EJ, Smith AR, Hagen TM (2009) Alpha-lipoic acid as a dietary supplement: molecular mechanisms and therapeutic potential. Biochim Biophys Acta 1790(10): 1149-1160.

6. Suh SH, Lee KE, Kim IJ, Kim O, Kim CS, et al (2015) Alpha-lipoic acid attenuates lipopolysaccharide-induced kidney injury. Clin Exp Nephrol 19(1): 82-91.

7. Khalili M, Soltani M, Moghadam SA, Dehghan P, Azimi A, et al (2017) Effect of alpha-lipoic acid on asymmetric dimethylarginine and disability in multiple sclerosis patients: A randomized clinical trial. Electron Physician 9(7): 4899-4905.

8. Huang YP, Jin HY, Yu HP (2017) Inhibitory effects of alpha-lipoic acid on oxidative stress in the rostral ventrolateral medulla in rats with saltinduced hypertension. Int J Mol Med 39(2): 430-436.

9. Di Domenico F, Barone E, Perluigi M, Butterfield DA (2015) Strategy to reduce free radical species in Alzheimer's disease: an update of selected antioxidants. Expert Rev Neurother 15(1): 19-40.

10. Gomes MB, Negrato CA (2014) Alpha-lipoic acid as a pleiotropic compound with potential therapeutic use in diabetes and other chronic diseases. Diabetol Metab Syndr 6(1): 80.

11. Anderson G, Maes M (2014) Oxidative/nitrosative stress and immunoinflammatory pathways in depression: treatment implications. Curr Pharm Des. 20(23): 3812-3847.

12. Koriyama Y, Nakayama Y, Matsugo S, Kato S (2013) Protective effect of lipoic acid against oxidative stress is mediated by Keap1/Nrf2dependent heme oxygenase- 1 induction in the RGC-5 cellline. Brain Res 1499: 145-157.

13. Farr SA, Price TO, Banks WA, Ercal N, Morley JE (2012) Effect of alpha-lipoic acid on memory, oxidation, and lifespan in SAMP8 mice. J Alzheimers Dis 32(2): 447-455.

14. Erdi MF, Guney O, Kiyici A, Esen H (2011) The effects of alpha lipoic acid on cerebral vasospasm following experimental subarachnoid hemorrhage in the rabbit. Turk Neurosurg. 21(4): 527-533.

15. Aliev G, Li Y, Palacios HH, Obrenovich ME (2011) Oxidative stress induced mitochondrial DNA deletion as a hallmark for the drug development in the context of the cerebrovascular diseases. Recent Pat Cardiovasc Drug Discov 6(3): 222-241.

16. De Araújo DP, LobatoRde F, Cavalcanti JR, Sampaio LR, Araújo PV, et al (2011) The contributions of antioxidant activity of lipoic acid in reducing neurogenerative progression of Parkinson's disease: A review. Int J Neurosci 121(2): 51-57.

17. Erşahin M, Toklu HZ, Cetinel S, Yüksel M, Erzik C, et al (2010) Alpha lipoic acid alleviates oxidative stress and preserves blood brain permeability in rats with subarachnoid hemorrhage. Neurochem Res 35(3): 418-428. 
18. Militão GC, Ferreira PM, de Freitas RM (2010) Effects of lipoic acid on oxidative stress in rat striatum after pilocarpine-induced seizures. Neurochem Int 56(1): 16-20.

19. Head E, Nukala VN, Fenoglio KA, Muggenburg BA, Cotman CW, et al (2009) Effects of age, dietary, and behavioral enrichment on brain mitochondria in a canine model of human aging. Exp Neurol 220(1): 171-176.

This work is licensed under Creative Commons Attribution 4.0 License

DOI: 10.19080/NAPDD.2017.03.555612
20. Goraca A, Asłanowicz-Antkowiak K (2009) Prophylaxis with alphalipoic acid against lipopolysaccharide-induced brain injury in rats. Arch Immunol Ther Exp (Warsz) 57(2): 141-146.

21. Salinthone S, Yadav V, Bourdette DN, Carr DW (2008) Lipoic acid: A novel therapeutic approach for multiple sclerosis and other chronic inflammatory diseases of the CNS. Endocr Metab Immune Disord Drug Targets 8(2):132-142.

\section{Your next submission with Juniper Publishers} will reach you the below assets

- Quality Editorial service

- Swift Peer Review

- Reprints availability

- E-prints Service

- Manuscript Podcast for convenient understanding

- Global attainment for your research

- Manuscript accessibility in different formats ( Pdf, E-pub, Full Text, Audio)

- Unceasing customer service

Track the below URL for one-step submission https://juniperpublishers.com/online-submission.php 